\title{
Editorial: Fossil Record says goodbye to Copernicus - collaboration with Copernicus, a decisive phase in the history of Fossil Record
}

\author{
Florian Witzmann $^{1, \mathbf{i}}$, Carolin Haug ${ }^{2, \mathbf{i}}$, Christian Klug ${ }^{3, \mathbf{i}}$, Johannes Müller ${ }^{1, \mathbf{i}}$, Torsten M. Scheyer ${ }^{3, \mathbf{i}}$, and \\ Alexander R. Schmidt ${ }^{4, i}$ \\ ${ }^{1}$ Museum für Naturkunde, Leibniz-Institut für Evolutions- und Biodiversitätsforschung, Invalidenstraße 43, \\ 10115 Berlin, Germany \\ ${ }^{2}$ Biocenter Department of Biology II and GeoBio-Center, LMU Munich, Großhaderner Str. 2, \\ 82152 Planegg-Martinsried, Germany \\ ${ }^{3}$ Paläontologisches Institut und Museum, Karl-Schmid-Strasse 4, 8006 Zurich, Switzerland \\ ${ }^{4}$ Geobiology Group, Evolution of Land Plants \& Development of Terrestrial Ecosystems, \\ Geoscience Centre, University of Göttingen - GZG, Goldschmidtstr. 3, \\ 37077 Göttingen, Germany \\ $\mathbf{i}_{\text {FR }}$ chief editor
}

Correspondence: Florian Witzmann (florian.witzmann@mfn.berlin)

Published: 17 December 2021

The following probably comes as a surprise for many authors in the field of palaeontology: Fossil Record will change its publisher so that collaboration with Copernicus Publications will end on 31 December 2021. This change is due to a new public procurement, which had to be carried out by the Museum für Naturkunde Berlin as a public institution according to the requirements of the Berlin Senate. We want to say "goodbye" and "thank you" to Copernicus with a short reflection on the past 8 years of collaboration in which Fossil Record became an open-access journal, refined its image and entered the top quartile of palaeontological scientific journals.

After Fossil Record was founded in 1998 as the palaeontological journal of the Museum für Naturkunde Berlin by Hans-Peter Schultze under the name Mitteilungen aus dem Museum für Naturkunde in Berlin, Geowissenschaftliche Reihe, it was particularly the commitment of the former editor Dieter Korn that the journal became SCIE-listed in 2009. In early 2014, Fossil Record started collaboration with Copernicus to become a scientific open-access journal. The directorate of the Museum für Naturkunde and the editors had realised the multiple advantages of open access and that this mode of publication was probably the future in science. The transition to open access was a pivotal point in the his- tory of Fossil Record. Initially, the journal faced several difficulties, and it was not clear at all if Fossil Record would survive. The two issues of the first volume published with Copernicus (Vol. 17, 2014) contained only five publications. The first important step to overcome this decline and to advance Fossil Record was undertaken in close cooperation with Copernicus by increasing the visibility of the journal via intensive advertising, e.g. at major international scientific conferences and via social media. Furthermore, Copernicus distributed Fossil Record articles to a variety of databases and abstracting and indexing services. Likewise important was the support by the directorate, which has taken over the article processing charges for authors since the beginning, and the steady support of the publication management of the Coordination Office for Scientific Publishing at the Museum für Naturkunde. Remarkably, Fossil Record is still one of the very few open-access journals in its discipline that does not have page charges for authors. Additionally, the short duration from the initial manuscript submission to publication (on average 104 days), the clearly arranged and user-friendly online submission system, and the tireless advertisement in the scientific community helped to attract more and more authors from all over the world. A few data may illustrate this trend: in 2014, Fossil Record received 11 submissions; in 
2021, 44 manuscripts have been submitted so far. The journal impact factor increased from 0.591 in 2014 to 2.091 in 2021, and Fossil Record is thus one of the most frequently cited pure palaeontological journals worldwide. While most authors of the journal were affiliated with the Museum für Naturkunde Berlin in the past, the vast majority of submissions now comes from institutions outside of Germany. One highlight of the past 8 years was the publication of the special issue "Secondary adaptation of tetrapods to life in water - Proceedings of the 8th International Meeting, Berlin 2017" in 2017-2018, which encompasses nine scientific articles.

Steady intense communication between publication management of the Museum für Naturkunde, editors and Copernicus further increased visibility and standing of the journal in the scientific community. Specific suggestions made by the Copernicus team led - for example - to changes in the editorial board, which became expanded and more diverse and international (a process that is, however, still ongoing).
The increasing reputation and success of Fossil Record in the scientific community as it stands today was only possible with an active, open-minded publisher such as Copernicus. Communication between Copernicus and the editorial board or the publication management was always smooth and constructive, and problems were solved quickly. The feedback from the authors was likewise always positive. Our authors frequently acknowledged the fast handling of the manuscripts as well as the quick replies and the excellent support by Copernicus. We, the editorial board of Fossil Record, would like to express our sincerest thanks to the whole Copernicus team for the 8 years of successful and trustworthy collaboration. From 1 January 2022 onwards, Fossil Record will be published by Pensoft Publishers like the other two journals of the Museum für Naturkunde Berlin, Zoosystematics and Evolution and Deutsche Entomologische Zeitschrift. The Museum für Naturkunde Berlin will remain the publishing institution. We are looking forward to a successful new cooperation! 